\title{
da exclusão a um modelo identitário de inclusão: a deficiência como paradigma biopolítico*
}

\author{
pedro angelo pagni ${ }^{1}$ \\ universidade estadual paulista - brasil
}

resumo

O deficiente tem sido objeto de exclusão no ambiente escolar. Historicamente, os argumentos utilizados para tal seriam os de que escaparia aos propósitos disciplinares da escola e, ao ser classificado como anormal, deveria ser destinado ao governo de outra instituição que, se não o corrigisse, o privaria da vida social. Recentemente, no caso do Brasil e de outros países, tais argumentos sofreram um deslocamento no sentido de buscar a inclusão do deficiente aos dispositivos e às instituições que os preparam para o exercício de uma função social e para o mercado. Nesse cenário atual, a categoria foucaultiana de biopolítica tem sido utilizada pela literatura acadêmica para elaborar um diagnóstico do papel ocupado pela deficiência tanto para problematizar as chamadas políticas de inclusão quanto para apresentar alternativas para o acolhimento dessa diferença ética em instituições como a escola. Desse ponto de vista, este artigo parte da constatação da necessidade de aprimorar a referida categoria, constitutiva de um diagnóstico mais amplo do presente e elaborada entre o final dos anos 1970 e meados dos anos 1980, recorrendo a outras publicações mais recentes do campo de estudos foucaultianos, para tornar seu uso um pouco mais preciso e para melhor focalizar o lugar ocupado pela deficiência no cenário biopolítico atual. Para tanto, recorremos aos estudos de Robert Castel, Paul Rabinow e Francisco Ortega para reelaborar o uso dessa categoria e atualizá-la em vistas a atender as demandas das formas de governamentalidade e das tecnologias de biopoder emergentes com as políticas de inclusão e, especificamente, a compreender a conversão da deficiência como modelo jurídico e administrativo em paradigma biopolítico. Interessa-nos, ao reconstruir esse percurso e diagnóstico, mostrar o quanto as políticas de inclusão do deficiente, por um lado, atendem as demandas de uma racionalidade econômica implementada no neoliberalismo e, por outro, na medida em que os seus modos éticos de existência também escapam ao excessivo controle eficiente da vida, o quanto geram focos de experiência e de resistência à essa atual configuração da biopolítica, criando outros modos de subjetivação.

palavras-chave: biopolítica; inclusão; deficiência; resistência.

\section{since the exclusion to an identity model of inclusion: the deficiency as biopolitical paradigm}

abstract

The disabled has been the subject of exclusion in the school environment. Historically, the arguments used for this would be that escape to disciplinary purposes and school, to be classified as abnormal, should be aimed at another government institution which, if not corrected, would deprive the social life. Recently, in the case of Brazil and other countries, these arguments were offset in the sense of seeking the inclusion of people with disabilities to devices and institutions that prepare for a social function and to the market. In this scenario, the category foucaultdan of biopolitics has been used by academic literature to develop a diagnostic of the role occupied by the disabilities both to discuss the so-called inclusion policies as to present alternatives to the admission of this difference in ethics

${ }^{1}$ E-mail: pedropagni@gmail.com 
institutions such as school. From this point of view, this article part of the realization of the need to improve this category, a wider diagnosis constitutive of this drawn-out between the late 1970 and the mid-1980, using other latest publications of the field foucauldians studies, to make their use a little more precise and to better focus on the place occupied by the deficiency in the current scenario biopolitics. To this end, we resorted to the studies of Robert Castel, Paul Rabinow and Francisco Ortega to re-shape the use in this category and update it in order to meet the demands of work and forms of biopower technologies emerging with inclusion policies and, specifically, to understand the conversion of disabilities as legal and administrative model in a biopolitics paradigm. We are interested in, to rebuild this course and diagnosis, show how the policies of inclusion of people with disabilities, on the one hand, meet the demands of an economic rationality implemented in neo-liberalism and, on the other, to the extent that their ethical modes of existence also are beyond the effective control of excessive life, how generate sources of experience and of resistance to this current configuration of biopolitics by creating other modes of subjectivation.

keywords: biopolitics; inclusion; disabilities; resistance.

\section{de la exclusión hasta un modelo identitario de inclusión: la discapacidad como un paradigma biopolítico}

resumen

Las personas con discapacidad han sido objeto de exclusión en el ambiente escolar. Históricamente, los argumentos utilizados para esto sería huir a los propósitos disciplinares y escuela, para ser clasificado como anormal, debe encaminarse a otra institución de gobierno que, si no le corrige, le privaría a la vida social. Recientemente, en el caso de Brasil y otros países, tales argumentos fueron desplazados en el sentido de buscar la inclusión de personas con discapacidad a los dispositivos y las instituciones que preparan para una función social y el mercado. En este escenario, la categoría foucaultiana de biopolítica ha sido utilizada por la literatura académica para desarrollar un diagnóstico de la función de la discapacidad tanto para discutir las dichas políticas de inclusión como para presentar alternativas a la admisión de esta diferencia ética en las instituciones como la escuela. Desde este punto de vista, este artículo tiene como punto de partida a la necesidad de perfeccionar esta categoría, planteada en un diagnóstico más amplio del tiempo presente y construida teóricamente entre finales de los años 1970 y los inicios de 1980, con otras publicaciones más recientes de los estudios del campo foucaultiano, que hacen su uso un poco más preciso y se centran más en el lugar ocupado por la deficiencia en el actual escenario de la biopolítica. Para ello, hemos recurrido a los estudios de Robert Castel, Paul Rabinow y Francisco Ortega para dar nueva forma a la utilización de esta categoría y actualizarla con el fin de satisfacer las demandas de trabajo y formas de biopoder tecnologías emergentes con las políticas de inclusión y, en concreto, para entender la conversión de la discapacidad como modelo judicial y administrativo en un paradigma de la biopolítica. Nos interesa, para reconstruir este curso y diagnóstico, mostrar cómo las políticas de inclusión de personas con discapacidad, por un lado, responden a las exigencias de una racionalidad económica implementada en el neoliberalismo y, por otra parte, en la medida en que sus modos éticos de existencia también están fuera del control efectivo de la vida excesiva, producen fuentes de experiencia y de resistencia a esta configuración actual de la biopolítica mediante la creación de otros modos de subjetivación.

palabras clave: biopolítica; inclusión; discapacidad; resistencia. 
da exclusão a um modelo identitário de inclusão: a deficiência como paradigma biopolítico*

O deficiente tem sido objeto de exclusão no ambiente escolar. Historicamente, os argumentos utilizados para tal seriam os de que escaparia aos propósitos disciplinares da escola e, ao ser classificado como anormal, deveria ser destinado ao governo de outra instituição que, se não o corrigisse, o privaria da vida social. Mais recentemente, no caso do Brasil e de outros países, tais argumentos sofreram um deslocamento no sentido de buscar a inclusão do deficiente aos dispositivos e às instituições que visam prapará-los ao exercício de uma função social ou no mercado de trabalho, muitas vezes, compreendendo que essa seria forma de poderem ser introduzidos e integrados ao mundo, como se a ação daqueles sobre este, como a de todos os seus demais atores, se restringisse somente à vida funcional e à atividade profissional.

Alguns prenúncios da crítica às formas de controle da vida podem ser encontrados, dentre alguns autores já clássicos, na obra tardia de Michel Foucault, desde o momento em que elabora a noção de governamentalidade ${ }^{2}$ e,

\footnotetext{
2 A noção de governamentalidade é criada por Michel Foucault para tratar do que denomina de formas de governos emergentes da passagem do Estado Soberano para o Estado Moderno, sobretudo, quando este último aprimora por meio das instituições sociais e das diversas artes que nelas circulam para governar a população. Em geral, segundo Foucault (1990), esta primeira forma de governamentalidade se caracteriza como uma forma de governamentalidade descendente, enquanto que as formas de organização dos movimentos que reagem a esta última e são empreendidas pela própria população em vistas a ampliar a sua participação na vida pública ou, mesmo, se apresentar como uma força junto ao Estado é denominada de governamentalidade ascendente. Em um de seus últimos cursos, em que trata do Governo de si e dos outros, ao analisar o que denomina de governamentalização, isto é, as formas de governo de si e do outro que compreendem os seus jogos com a crítica ou com o não querer ser governado de determinada forma, expandindo a noção para compreender modos de governo que se estruturam nas relações interpessoais e que se erige a partir da ética de si nos mundos grego e romano. Foucault (2010) parece expandir desse modo essas formas de governo a um jogo, não somente ascendente ou descendente, mas também diagonal ou, mesmo, transversal a essas forças, que fazem da democracia antes do que uma isonomia quantitativa, uma diferença qualitativa entre os diversos agrupamentos sociais, dando visibilidade as minorias emergentes, por assim dizer. Nesse sentido, ao expandir as formas de governo à formação ética do sujeito, articula a governamentalidade a ação desse último, que ultrapassa as formas anteriores e que em geram emergem como um acontecimento ou, se preferirem, aos modos usuais de governo da via e como uma atitude que lhes resiste, criando modos de existência outros. Por isso, a literatura compreende essa noção como sendo elaborada na passagem da fase genealógica e política de Foucault para o momento em que se ocupa da formação ética do sujeito e dos processos de subjetivação, caso se siga a divisão didática proposta por Veiga-Neto (2004).
} 
da exclusão a um modelo identitário de inclusão: a deficiência como paradigma biopolítico*

concomitantemente, a de biopolítica ${ }^{3}$, até os seus últimos cursos, dentre os quais se destacam a temática dos homens infames e do governo dos vivos, embora neste caso não se destinando a tratar diretamente da conjuntura política contemporânea. A literatura sobre a temática da inclusão do deficiente em instituições sociais como a escola a partir dessas noções foucaultianas, transversalmente a vários campos, não é muito extensa, mas ela colocou em circulação algumas interpretações sobre os problemas dos modos tanto de governo sobre a deficiência, nos termos assinalados pelas várias perspectivas de análise presentes no livro organizado por Shelley Tremain (2005), quanto das relações entre inclusão escolar e biopolítica, tal como circunscritos na coletânea organizada por Elí T. Henn Fabris e Rejane Ramos Klein (2013). Em outras ocasiões, também procurei adensar essa literatura sobre o assunto, ao retomar o diagnóstico foucaultiano sobre a biopolítica neoliberal para problematizar os discursos e as políticas de inclusão escolar e compreender a sua articulação com uma racionalidade econômica e com o processo de globalização dos modos de vida pautados pelo empresariamento de si (PAGNI, 2015). Contudo, parece haver certa limitação do referido diagnóstico para se pensar o tempo

\footnotetext{
${ }^{3}$ A biopolítica se constitui em um conjunto de tecnologias de biopoder que, desde o século XVIII, se configura numa forma de exercer um poder sobre a vida da população, particularmente, se responsabilizando pela sua saúde, pelos cuidados com a procriação e o sexo entre os seus integrantes, com vistas a formar políticas capazes de governar, de regulamentar e normalizar os seus modos de existência, tomando-a como objeto de várias ciências para tal e formando um corpo social, relativamente, homogêneo. Antes de estar sujeito ao império do poder soberano a quem caberia o direito sobre a sua morte e ao poder disciplinar ou, de uma, "anátomo-política do corpo" (FOUCAULT, 1997), a biopolítica se ocuparia de administrar a vida da população, evitando que morra, para fazê-la viver, se ramificando pelas diversas artes de governo e atuando sobre o corpo de cada indivíduo para que este último a governe por e para si mesmo, segundo os saberes científicos e as tecnologias do biopoder vigentes. Tais saberes e tecnologias, por sua vez, trazem a promessa de prolongarem a sua existência, ainda que para torna-la mais produtiva e ao mesmo tempo menos prenhe de vida, enquanto que a sua liberdade se reduz a esse jogo de perder a vivacidade para servir a algo que lhe assegure a sobrevivência, com as possibilidades de viver somente dentro de uma racionalidade econômica, algo que fundamentará o liberalismo. No neoliberalismo, de acordo com Foucault (2008) a biopolítica se torna um modo de existência, marcado pelo empresariamento de si e pela formação do capital humano, encontrando aí e nessa espécie de individuação um processo de coesão e de constituição do corpo social. Ao problematizar tanto aquela quanto essa forma de liberdade, segundo Judith Revel (2005, p. 27), nas suas obras tardias e em seus cursos no final da vida, Foucault propõe uma rearticulação da política com a ética ou, melhor seria dizer, a bipolítica "representaria a passagem do político ao ético" em sua obra. Isso ocorreria na medida em que coloca a vida não apenas como lócus de controle pelas tecnologias cada vez mais sofisticadas de biopoder e da política, como também de um contra-poder ou de algo que extrapola qualquer dominação plena e resiste ao poder que pretende subjuga-la, criando outras formas de subjetivação.
} 
presente, em razão da alteração das epistêmes em torno das quais se justificam as formas de governamentalidade e as tecnologias de biopoder empregues a partir das décadas de 1970 até nossos dias, assim como as outras configurações de poder que trazem para formas de controle da vida, tornando-as cada vez mais imperantes e excessivas no cenário neoliberal atual. Por sua vez, as linhas de fuga que esgarçam aquelas práticas e resistem a essas formas de dominação, por assim dizer, se também se modificaram nos últimos anos, indicando formas de escape aos processos de subjetivação que se pautam seja numa ascese atlética, seja nas políticas inclusivas mais recentes. Se esses processos de subjetivação se realizaram no sentido de adaptar os deficientes às normas e às funções diversas do que as do passado, tornando-os mais produtivos e, sobretudo, integrados às redes de consumo atuais, outros desafios éticos também surgiram e modos de existência outros se produziram no sentido de resistirem, transversalmente, às formas de governamentalidade e as tecnologias de biopoder em circulação. É esse movimento que gostaria de retratar neste artigo, em vistas a não somente elaborar um diagnóstico um pouco mais preciso acerca do papel da deficiência na conjuntura biopolítica atual, como também a apontar, ainda que breve e teoricamente, os indicativos desses modos de existir deficientes como uma das possibilidades de resistência atual.

\section{de modelo jurídico à paradigma da biopolítica: obscuridades da deficiência}

Para situar a deficiência no presente gostaria de recorrer a diagnósticos acerca de seu papel nas sociedades pós-disciplinares como as nossas, nos termos analisados por Castel (1984) e sintetizados por Rabinow (1999), com o intuito de corroborar e, principalmente, aprimorar as análises de Foucault (2008), nos termos anteriormente expostos em outras ocasiões (PAGNI, 2015a; 2015b).

Para Robert Castel (1984), nas sociedades pós-disciplinares, observou-se um conjunto de críticas às intervenções médico e psicológicas ocorridas desde o século XIX, em virtude de seu caráter estritamente coercitivo, de seu modelo segregativo e assistencial, que garantiu a exclusão de certas formas de desvio. Durante toda a primeira metade do século $X X$, as intervenções tanto de alguns Estados modernos 
quanto de iniciativas de organizações privadas médicas e psicológicas tentaram começar a substituir esse modelo de exclusão jurídica e administrativa por outro que procurou gerir as disfunções das populações e suas vidas disformes. Em vistas a governa-las e incluí-las a uma ordem instituída, atribuem-lhe um papel funcional na sociedade existente e na sociedade civil. Essa tendência inclusiva das ações estatais e de organizações médicas e psicológicas, porém, parece conviver com uma terceira estratégia de governamentalidade das populações, que teria emergido em escala global, desde os anos 1970.

Para tal estratégia não se trataria de corrigir os desvios sociais para manter a ordem instituída, mas "construir um mundo psicológico e social ordenado a partir do trabalho sobre o material humano" no sentido não somente de "reparar ou prever a deficiência", como também de "programar a eficiência" (CASTEL, 1984, p. 221). Afinal, de acordo com o sociólogo francês, as sociedades pós-disciplinares não mais se erigiriam pela imposição de coerções, mas pela "organização do fator humano em função das novas figuras que adota a necessidade social" (CASTEL, 1984, p. 221).

Essas novas figuras são não apenas os integrantes da população que desempenham com eficácia a função que exerce na sociedade civil e que medianamente atendem as necessidades que lhes são socialmente impostas, como também aqueles que estão abaixo ou muito além dessa média estabelecida. Nesse sentido, não se trataria de reparar ou prevenir as anomias sociais que emergem de parte dessa população com disfunção orgânica, psíquica ou, em uma palavra, com alguma deficiência, nas sociedades pós-disciplinares. Tampouco se deveria selecionar os superdotados e com altas habilidades dessa mesma população para otimizar e compensar os riscos proporcionados pelos chamados deficientes. Ao invés de tratar os deficientes como portadores de alguma doença a ser tratada, dever-se-ia preconcebê-los como seres que apresentariam um desenvolvimento atrasado em relação aos outros - abaixo ou acima da média estabelecida e, portanto, de uma norma em vigência na sociedade - e que necessitariam aprender habilidades para que desempenhem medianamente alguma função ou otimizem ainda mais qualquer de suas excepcionalidades. Para tanto seria preciso que de 
antemão já se soubesse quem do contingente populacional apresentasse maior risco e devesse ter a sua vida acompanhada de perto por agentes sociais que não somente os mapeiam, como também definem uma diversidade de normas a partir dos conhecimentos e dos dispositivos sociais que os classificam e distribuem-nos em conformidade a diferentes registros de normalidade. Assim, seria necessário gerenciar essas redes que se formam a partir dessa distribuição de acordo com os riscos de cada integrante da população para que aquilo que colocasse em xeque a sua homogeneidade ou a sua unicidade, pudesse ser neutralizado e controlado, não mais com os velhos mecanismos de coerção estatal, mas agora em nome de sua diversidade, que lhe traria uma suposta garantia de liberdade individual.

Ao interpretar esse diagnóstico de Robert Castel, Paul Rabinow (1999) argumenta o seguinte:

\begin{abstract}
A prevenção moderna é antes de tudo o mapeamento de riscos. O risco não é o resultado de perigos específicos colocados pela presença imediata de uma pessoa ou um grupo de pessoas, mas sim a fusão de "fatores" impessoais que tornam um risco provável. Assim, a prevenção e a vigilância, não do indivíduo, mas sim de prováveis ocorrências de doenças, anomalias, comportamentos desviantes a serem minimizados, e de comportamentos saudáveis a serem maximizados. Estamos aos poucos abandonando a antiga vigilância face-a-face de indivíduos e grupos já conhecidos como perigosos ou doentes, com finalidades disciplinares ou terapêuticas, e passando a projetar fatores de risco que desconstroem e reconstroem o sujeito individual ou grupal, ao antecipar possíveis lei de irrupções de perigos, através da identificação de lugares estatisticamente localizáveis em relação a normas e médias. Por meio do uso de computadores, os indivíduos que compartilham certas características ou conjunto de características podem ser agrupados de uma maneira que é não apenas descontextualizada de seu ambiente social, mas também nãosubjetiva - no duplo sentido de atingida objetivamente e de não se aplicar a um sujeito em nada semelhante ao antigo sentido da palavra, isto é, o sofrimento, significativamente situado, integrador de experiências sociais, históricas e corporais. (RABINOW, 1999, p. 145)
\end{abstract}

No âmbito desse agrupamento não somente a ciência e a tecnologia genética passariam a circunscrever identidades em torno de modos de existências definido a partir de características fenotípicas e genotípicas, denominadas de biossociabilidades por Rabinow (1999), como também o modelo da deficiência a ser compensada passaria a substituir o da doença a ser tratada ou curada, como justificativa para uma racionalidade que amplia o controle sobre a vida e a estende no sentido de torna-la cada vez mais produtiva. Um novo paradigma 
administrativo e jurídico parece emergir assim na gestão dos riscos se instituindo em algumas sociedades europeias, com uma rápida e posterior generalização para todo o mundo, especialmente, nos Estados Nacionais que ainda se preocupavam em atuar com políticas compensatórias para oferecer condições para que os integrantes de suas respectivas populações pudessem superar individualmente seus déficits.

Nesse sentido, cada indivíduo se empreenderia para ser eficiente no desempenho de uma dada função, por um lado, e graças a tais dotações adquiridas por ele, independente dos déficits que possua, um maior contingente de pessoas integradas ao que estatisticamente pode ser considerado como dentro do desvio padrão de uma determinada normalidade da população, por outro. Esse paradigma jurídico e administrativo começou a se instituir nos anos 1970, em algumas sociedades como na França, se fundando na necessidade de se prevenir a deficiência manifesta na idade adulta, constituindo uma série de artes de governo e de tecnologias capazes de atuar desde a infância na prevenção dos riscos de sua população. A deficiência seria central para esse paradigma, já que, de acordo com Castel, considera-se o deficiente como toda pessoa 'que, em consequência de seu estado físico, mental, de suas características ou situação social, sofra transtornos decorrentes de "déficits", quer dizer, limitações, problemas em relação ao que é considerado normal' (1984, p. 128). Na medida em que o normal é definido pela média das capacidades e das oportunidades da maioria dos indivíduos de uma determinada sociedade, esses déficits causadores da deficiência seriam uma espécie de inadaptação à vida social da qual crianças, adolescentes e adultos fariam parte, pois, teriam dificuldades mais ou menos grandes para ser e atuar como os demais integrantes da população. Especificamente, dessa forma, o deficiente seria “a pessoa que, em razão de sua incapacidade física ou mental, de seu comportamento psicológico ou de sua falta de formação, é incapaz de prover as suas próprias necessidades ou exige constantes cuidados ou se encontra marginalizada tanto por suas próprias características como as das coletividades nas quais vive" (CASTEL, 1984, 129). 
Se essa incapacidade é uma ausência de formação ou uma dependência constante de outrem ou, ainda, qualquer característica individual ou coletiva que coloque à margem da vida social tais sujeitos denominados de deficientes, os déficits mencionados poderiam ser compensados de alguma forma, graças à oferta de condições para que cada qual se desenvolva. Em tese, tal desenvolvimento autoindividual propugnaria alcançar linhas bem próximas à normalidade, oferecidas pelas políticas públicas de Estado a partir de uma gestão preventivo-educacional dos riscos e de ações que possibilitassem a tais segmentos se integrarem à população da qual fazem parte. Mais do que a necessidade da atuação conjunta de várias instituições para garantir que o investimento naqueles que apresentam alto ou baixo potencial de risco, reiterando certa hierarquização por essa lógica identitária e essa racionalidade econômica, o investimento na educação das crianças e dos mais jovens passaria a ser uma meta estratégica das várias artes de governo que a compreendem.

O alcance dessa meta, por um lado, auxiliaria a essas instituições a alimentar os dados para a gestão desses riscos pelo Estado que, por sua vez, regulamentaria as normas, asseguraria a participação das identidades dos chamados grupos de risco e legitimaria os acordos que as legitimariam na espera pública, restringindo ou ampliando o seu poder de ação e o seu espaço. Por outro lado, se alcance garantiria uma forma de legitimação, de segurança e de normalidade cada vez mais objetiva ou, melhor seria dizer, objetivista, ainda que definida por meio do consenso travestida por aportes da ciência.

Rabinow (1999) procura aprofundar a análise da deficiência como a base desse novo modelo jurídico e administrativo que, com o apoio de certos saberes sociológicos, estatísticos e médico, resultou da racionalidade econômica e se centrou na gestão dos riscos, quase elevando-o ao patamar de um paradigma biopolítico. O autor faz isso ao estender esse diagnóstico aos anos 1990 e o aprimorar no sentido de mostrar como recebeu a sustentação do desenvolvimento das ciências genéticas e, particularmente, de projetos como o genoma. Ele mostra ainda como essa busca de um maior objetivismo por parte dos fundamentos daquele modelo jurídico e administrativo enunciado por Robert Castel, 
legitimaram uma série de dispositivos e tecnologias biopolíticas nas duas últimas décadas. Assim, cada vez menos se procurou perceber a relação com deficiência e com os deficientes como mediados por relações intersubjetivas e pelas experiências singulares que as compreendem, já que ao ignorar tais mediações seria mais fácil caracterizá-la como produtora de formas de agrupamento social, distribuí-la em conformidade com os déficits dos integrantes desse determinado grupo, avaliando suas potencialidades e riscos.

Isso foi possível, primeiro, porque se procurou naturalizar a cultura por meio de uma ciência que erigiu a patologia como um estatuto de ciências do social e, por sua vez, pela elaboração de um campo específico desta - a sociobiologia que seria capaz de acumular os dados patológicos da população. Com esse campo de especialização, mais recentemente, não somente a cultura que a compreendia se naturalizou ao máximo, como também a natureza que designou se artificializou, graças à emergência das tecnologias genéticas. Por isso, Rabinow perspectivou a partir desse diagnóstico o seguinte:

No futuro, a nova genética deixará de ser uma metáfora biológica para a sociedade moderna, e se tornará uma rede de circulação de termos de identidade e lugares de restrição, em torno da qual e através da qual surgirá um tipo verdadeiramente novo de autoprodução: vamos chamá-lo de biossociabilidade. Se na sociobiologia a cultura é construída com base numa metáfora da natureza, então na biossociabilidade a natureza será modelada na cultura compreendida como prática; ela será conhecida e refeita através da técnica, a natureza finalmente se tomará artificial, exatamente como a cultura se tornou natural. (1999, p. 143-44)

A biossociabilidade seria a possibilidade, inclusive, de termos agrupamentos sociais, além de normas que reguladoras de suas existências, em torno de bioidentidades, isto é, de traços fisionômicos, genotípicos e fenotípicos, características comportamentais, dentre outros, definidos por códigos genéticos, antecipando os riscos que corremos e antecipando os acidentes que eventualmente teremos. Diferentemente dos métodos eugênicos que procuravam controlar os cruzamentos raciais supostamente perigosos e regulamentar os casamentos na ordem social, as formas de biossoabilidades regimentam grupos em torno de códigos supostamente objetivos, a fim de que os acidentes que eventualmente produzam déficits e os tornem deficientes possam ser combatidos por tecnologias 
bastante específicas que agem sobre seus corpos e, efetivamente, artificializam a sua vida, fazendo dela uma peça pronta a ser montada, objeto de planejamento e elaboração consciente.

Nota-se nesse contexto a constituição de um campo específico do saber em que esse estado de vida deficiente se torna um objeto a ser estudado para mapear os riscos da população, com o intuito de haver uma justificativa plausível para que as políticas compensatórias ofereçam condições de superação dos déficits e, com isso, se restabeleça uma suposta igualdade dessa parcela da população, na concorrência existente com aquela que não recebem a denominação "deficiente". Nessa conjuntura, se desenvolvem também políticas estatais ou mesmo de regulação do mercado com a finalidade de dispositivos e tecnologias específicas atuarem no sentido de propiciar a estes últimos aquelas condições, propiciadas graças à constituição daquele campo de saberes interdisciplinares, e, no limite, de seu fundamento na genética, o que garantira em tese certa aura de objetividade ao trato e às relações com os serem designados como deficientes.

No caso brasileiro, é numa conjuntura global como essa e pela perseguição de se adotar medidas estatais semelhantes às adotadas em outros países centrais do capitalismo que, desde meados dos anos 2000 - para não dizer, um pouco antes -, vem se procurando adotando algumas políticas de inclusão social e, particularmente, dos deficientes. Os efeitos e o acontecimento discursivo por elas produzidas, ao se desenvolver uma série de dispositivos, propor novas tecnologias fundamentadas em saberes e todos aparatos específicos, foram, em linhas gerais, por um lado, o da confecção de uma base jurídica capaz de garantir a possibilidade de trata-lo como um indivíduo igual aos outros, porque estariam lhes sendo dadas as condições para tal. Por outro lado, a elaboração de uma fundamentação capaz de convencer aos demais de que não somente os designados socialmente como "deficientes", mas todos e cada um seriam deficientes na medida em que, em algum momento da vida, teriam que enfrentar seus déficits, suas disfunções e deformações, já que estes fariam parte da condição humana. Em prol de certa promessa de igualdade, a diferença que constituem essas relações com a deficiência e com os deficientes torna-se obscurecida para não dizer encoberta por 
uma promessa formal - jurídica e ontologicamente justificáveis - de inclusão de todos a não mais uma norma única, geral, mas às normas múltiplas. E, por sua vez, esta multiplicidade de normas caracterizaria a diversidade constituída e a apresentaria como análoga às de certas culturas como a nossa, em vista a produzir muitas vezes agrupamentos sociais que se formam em função mais das identidades que os congregam do que da comunhão do que lhes é diverso.

\section{a deficiência entre sombras e luzes da diferença}

A partir dos anos 2000 o diagnóstico de Rabinow (1999), que parecia certo exercício de futurologia para os anos 1990, tendeu a se efetivar, caso se considere as interpretações de Francisco Ortega (2003; 2005; 2008). Em linhas gerais, essa tendência se efetivou em razão da forma como a vida passou a ser regulamentada pelas tecnologias do biopoder e por uma configuração da biopolítica que se expandiu das instituições estatais e privadas para os capilares da existência ordinária, passando pela cultura do corpo que, ao naturalizá-lo, artificializou as forças vitais que nele pulsam. Especificamente, ao considerar a biossociabilidade como uma forma de sociabilidade apolítica constituída por grupos de interesses privados, Francisco Ortega argumenta que tais agrupamentos não mais se dariam segundo critérios tradicionais "como raça, classe, estamento, orientação política, como acontecia na biopolítica clássica, mas segundo critérios de saúde, performances corporais, doenças específicas, longevidade, etc." (2005, p. 155). A partir desses critérios se criam novas formas de reconhecimento e de valores que têm por base "regras higiênicas, regimes de ocupação de tempo, criação de modelos ideais de sujeito baseados no desempenho físico", em vistas a "obter melhor forma física, mais longevidade", inspirada num "vocabulário médicofisicalista" que cada vez mais se popularizou (capacidade aeróbica, tônus muscular, taxas de colesterol, etc.) nos últimos anos e que adquiriu uma conotação quase moralizante (ORTEGA, 2005, p. 155) para a vida ordinária. Em torno desta nova forma de moralidade, vocabulário e princípios, boa parte das atividades sociais, lúdicas, religiosas, esportivas "são ressignificadas como práticas de saúde" e se exprimem numa forte tendência subjugadora da existência (ORTEGA, 2005, 
p.155). Tal subjugação se daria tanto com a criação de tecnologias de biopoder a partir da emergência dessa moralidade da saúde como das bio-asceses que a produzem ajustando a ela modos de subjetivação específicos, que funcionam em conformidade com seus critérios e fins.

Graças a tais dispositivos os sujeitos veriam a si mesmos na aparência corporal que exprimem, exigindo para tanto que as suas bio-identidades se constituíssem segundo parâmetros higiênicos, estéticos e médicos, assim como promovam um autocontrole, uma autovigilância e um autogoverno, encontrando no artifício da autoperitagem a fonte de sua própria identidade. E, mais do que isso, a autoperitagem se constituiria num imperativo para que esse sujeito guiasse sua vida por um conjunto de manuais, terapias, fitness, que permitiriam a compreensão do eu como um conjunto de práticas e um projeto de reflexividade definido pelo constante "processo de taxação contínua de informação e peritagem sobre nós mesmos" (ORTEGA, 2005, p. 157).

No interior de um modelo jurídico e administrativo centrado na deficiência se passa a um paradigma político para os deficientes- e de uma política que penetra em todos os capilares da vida mesma -, no qual estes últimos estariam excluídos, caso não se dispusessem a 'representar o papel designado para eles nos dramas baseados na realidade, como uma espécie de "modelos corajosos de ajustamento pessoal, esforço e realização"' (ORTEGA, 2005, p. 158). Isso porque, de um lado, os deficientes poderiam ser induzidos, desde o ponto de vista desse paradigma, a se ajustar à normalidade e à moralidade que o presumem, livrando parcialmente da associação da deficiência ao crime, ao mal e às aberrações, aos quais historicamente o associaram; de outro, o estereótipo do corpo lipoaspirado, malhado e padronizado idealmente existente emergente, na atualidade, fez com que a deficiência se estendesse a todos os corpos que não aí se enquadram, como o dos obesos, idosos, etc. Em decorrência dessa corrida em torno de uma normalidade dada por esse padrão corpóreo e essa moralidade da saúde, uma série de doenças debilitantes (bulimias, anorexias) foram geradas, resultantes dos fracassos de ajustamento e de uma série de problemas, trazendo muitas implicações psíquicas e, principalmente, éticas. Aumentou-se, dessa forma, o 
preconceito contra todo/as aquele/as que fracassam nessa ascética atlética exigida, assim como aqueles que não se adequam de alguma forma a ela, estendendo a deficiência para um grupo maior do que o existente, juntamente com a condição de marginalidade na média e na norma social que representa.

Em consequência dos efeitos desse modelo político biomédico, os deficientes (não restritos mais somente aos que até então assim eram chamados) passaram a reagir e a se organizar em torno de suas bio-identidades e a disputar um espaço de maior prestígio na sociedade, em vistas a demonstrar a superação dos riscos que representam e, consequentemente, uma estratégia de seu ajustamento às normas existentes dentro de múltiplos agrupamentos sociais. É nesse contexto político que os chamados "deficientes" atuam, conjuntamente com grupos de idosos, de self care e movimentos de auto-ajuda, de acordo com Ortega, "encorajados desde as perspectivas de governamentalidade neoliberais" (2005, p. 158). Dessa forma, conclui esse autor,

Os grupos e bioidentidades sociais constituídos na biossociabilidade por meio de práticas de bio-ascese se distinguem precisamente por deficiências a serem compensadas (deficiência da mulher frente ao homem, do negro frente ao branco, do gay frente ao heterossexual, do deficiente físico frente ao indivíduo fisicamente normal, dos velhos frente aos jovens, etc.). A política se dissolve em políticas particulares que aspiram compensar as deficiências de um grupo biopolítico determinado, cuja uma das consequências é o esquecimento de ideais sociais mais abrangentes. (ORTEGA, 2005, p. 158-159)

Essa forma de reação política ao modo como os deficientes são instados a se tornar como os demais e a se ajustar a uma ascese corporal moderna que requer um modelo atlético de superação dos déficits - muito longe da atlética do acontecimento exigida pela ascética antiga -, em busca de certa igualdade na disputa para compensar seus riscos iniciais, parece não ultrapassar a lógica da identidade e o princípio da racionalidade econômica que a regem. Afinal, essa forma de bio-identidade também se forma a partir de uma série de dispositivos difundidos na sociedade e em circulação nas instituições, constituindo um conjunto de tecnologias do biopoder, nos termos descritos anteriormente, aos quais os deficientes devem se submeter como qualquer pessoa, em busca de uma identidade restrita ao físico e ao seu desempenho. 
Quando isso não ocorre, se deixam conduzir, muitas vezes, por critérios de produtividade e que provém da esfera produtiva que restringem o corpo à sua eficácia neural e o sujeito ao cérebro, em vistas a mapear os riscos que cada um representa para o capital humano e aumentar a eficácia individual numa conjuntura de neuro-diversidades em que as diferenças são amenizadas e as deficiências eleitas como o principal alvo a ser combatido pelo empreendedorismo de si. A emergência dessa configuração mais recente do biopoder traz desafios ímpares nem tanto aos deficientes que apresentam limitações motoras em razão da idade ou de acidentes corporais, já que não necessitam mais se expor no que constituem suas particulares fragilidades, mas às deficiências e aos acidentes que produzem disfunções intelectuais mais severas.

Da transversalidade dos corpos sem cérebros aos cérebros sem corpos, do seio de uma cultura midiática e consumista aos índices de produção, essas neurodiversidades emergem em meados dos anos 2000, em consonância com o desenvolvimento da linguagem computacional e da neurociência, que passam a dar o aporte institucional às diversas artes de governo, dentre elas, as psicológicas e, no último decênio também, as pedagógicas.

A modificação corporal responde a um déficit identitário, constitui uma
suplência de identidade, um tipo de assinatura de si através da qual o
indivíduo se afirma na identidade escolhida, que difere daquelas que lhe
são atribuídas pelo olhar do outro.
No entanto, o repertório que o indivíduo dispõe para criar uma
identidade corporal, naturalizada, é finito, dado pelos próprios limites de
seu corpo. (...) Ao repertório limitado de identidades corporais opõe-se a
riqueza infinita da identidade psicológica ou mental em função da própria
imaterialidade do mental. Isto sem mencionar o engodo psíquico que
supõe localizar a identidade pessoal no corpo. Se o que somos está
exposto ao olhar do outro, somos privados da capacidade de fingir, de
dissimular, de esconder os sentimentos, as intenções, os segredos.
(ORTEGA, 2008, p. 494)

É curioso notar que nessa cultura em que as marcas artificialmente criadas no corpo, por meio de tatuagens, de piercings e de deformações provocadas por alargamentos, implantes, chegando até amputação de membros, procuram produzir uma identidade subjetiva. Tal identidade, nesse sentido, passa por uma espécie de imitação de formas de deficiências físicas, de sombras da anormalidade e da monstruosidade que a normalidade historicamente construída procurou 
excluir, parecendo encontrar nesses traços e marcas físicas o signo de um eu perdido.

Nesse contexto, a performatividade do corpo, inclusive dessa exposição da imitação artificial da deficiência física, passa a produzir uma espécie de diferenciação da homogeneidade da população e da normalidade exigida ao indivíduo. Mais do que isso, muitas vezes sugere uma excentricidade supérflua de quem procura aparentemente escapar de tais imperativos, mas para recair na ordem do consumo e em redes comunitárias movidas por uma bio-identidade. Tanto essa ordem quanto as redes que formam as bio-identidades apostam na promessa de que, já que todos seriam deficientes - ontologicamente falando -, o exercício de reconhecimento em relação aos chamados "deficientes", por si só, garantiria certa igualdade entre os indivíduos e, portanto, melhoraria a concorrência, a performatividade e a eficiência na produção, na medida em que encontrassem como os demais a satisfação no consumo.

O que é interessante é que parte dos deficientes físicos ou que trazem impressos no próprio corpo os seus traços fenotípicos, mais próximos à curva da normalidade característica de sua bio-identidade, também se valem desse dispositivo. Na medida em que as suas identidades vêm demarcada não por algum artifício, mas por um acidente efetivo, que os colocam nesse jogo atual da cultura corpórea, como no caso de alguém que não necessita de qualquer marca artificial para se exprimir, os deficientes já a trazem impressa em si, se obrigando a conviver com estas últimas ou a perecer e, com isso, produzindo um modo de vida próprio, afirmativo de sua existência. Contudo, esse modo de existência pouco ganha visibilidade por si mesmo, inclusive dos próprios deficientes, pois, graças a essa valoração cultural de algo supostamente negativo, também se subjugam às formas de bio-identidades imperantes, hiperbolizando as suas marcas físicas com tatuagens, piercings. Incluído por esse viés do consumo, ao qual todos estão integrados no mundo atual e com o qual também se identificam, o próprio deficiente físico, por vezes, acaba também deixando de exprimir o modo como vive para expor aos olhos alheios o que o outro deseja ver: uma deficiência travestida, artificial, que esconde outra perturbadora - a efetiva. 
Por isso, Georges Canguilhem (2009), no ensaio escrito duas décadas depois de O Normal e o Patológico, argumenta que o problema da anormalidade que precedeu a deficiência se refere muito mais à sombra que vemos e a uma normalidade construída de fora de nós mesmos do que esse outro que se apresenta e da vida que normaliza a existência desde sua imanência mesma. Desta perspectiva, o que, então, provocaria esse artificialismo da deficiência ou, se preferirmos, a sua ocultação para que não se a expusesse publicamente? Uma resposta possível é que, para além de queremos ser percebidos pelo outro e nos apresentarmos à comunidade somente pelo corpo que temos, no presente, buscaríamos uma identidade e uma diversidade centrada no cérebro. Esta sim mais substancial, menos superficial ou aparente, em substituição a velha alma ou a subjetividade esvanecida e indicada como um dos sintomas da contemporaneidade.

De acordo com Francisco Ortega, poderíamos encontrar aí certa "plasticidade" e, também, graças às "teorias, práticas e produtos que exploram a "neuroplasticidade", a multiplicidade, a criatividade e a singularidade capazes de atos de inovação na atividade produtiva, representando aí uma esperança do investimento no capital humano e de maior satisfação no âmbito do consumo. Nesse sentido a autossatisfação individual atenderia a uma demanda daquele olhar alheio. No entanto, pondera o mesmo autor, deve-se considerar que "a complexidade e a riqueza das experiências mentais não são reduzíveis à simplicidade e à pobreza das redes neurais ou das medidas neuroquímicas" (2008, p. 495), pois, se assim fosse deveríamos considerar como correspondente uma subjetividade rasa, vazia de emoções e de afetos, fraca de atitudes éticas e pobre em pensamentos, incapaz de produzir modos de existência que escapassem a um exercício meramente cognitivo.

Essa similaridade do deslocamento da identidade corporal para a cerebral, no persente, se dá de modo a neutralizar e tornar objetiva dessa forma a complexidade das experiências que formam o sujeito. Para tal, porém, é necessário que este seja descaracterizado quanto ao seu modo de ser, de pensar e de agir para subordiná-lo à homogeneidade de uma população que agora pode ser 
quantificada, medida e avaliada pelos recursos da informática (e não mais somente da estatística). Assim, esse sujeito seria tratado como um dado a mais no índice de funcionamento e de eficiência do sistema produtivo do mesmo modo que a população poderia responder aos gráficos e as linhas padrões similares aos da bolsa de valores, que emulam as pessoas a agirem em conformidade com as variações do mercado financeiro, como sugeriu Maurizio Lazzarato (2014).

Os exemplos dados por Ortega (2008) em relação às situações de autistas nos Estados Unidos parecem ilustrar bem o quanto alguns desses sujeitos também se valem daquilo que neles excede em relação ao seu desempenho e às suas habilidades intelectuais ou cerebrais para gerar um tipo novo de bio-identidade. Esta forma bio-identitária atual é marcada por uma alta performatividade e eficiência no campo do desempenho intelectual que, embora traga uma larga dificuldade para lidar com experiências emocionais e para constituir redes biossociais fora dessa neurodiversidade específica ou que extrapolem a uma lógica eminentemente identitária, representam um novo paradigma de produtividade. $\mathrm{O}$ fato de se expressarem e de alguns desses autistas protagonizarem uma luta pública para serem reconhecidos como grupo em torno dessa neurodiversidade e dessas qualidades associadas aos critérios produtivos de eficiência, excluem um largo contingente de sujeitos classificados dentro desse espectro, com níveis mais severos de déficits, de distúrbios e de dificuldades de inúmeras espécies, gerando a revolta de seus pais e cuidadores.

Estes últimos, por sua vez, ainda exigem o apoio das políticas estatais nos cuidados dispensados aos seus filhos ou às pessoas sob seus cuidados, até porque convivem de maneira aguda com uma deficiência intransponível e insuperável, sem qualquer possibilidade de integração funcional. Mesmo assim, as questões bioéticas comuns, que tanto uns quantos outros agrupamentos enfrentam, se referem às possibilidades de cura dada pelo fim de formas autistas dentro de seu amplo espectro, graças ao mapeamento genético, à sua correção ou à interrupção da gestação com fetos autistas, defendida por alguns integrantes dessa comunidade, assim como os modos de coexistência dos autistas com traços de altas com os de baixas habilidades. Afinal, também eles e alguns defensores da 
neurodiversidade vêm chamando atenção para "o perigo de que a valorização de ser deficiente esteja relacionada com a comparação e a hostilidade com os nãodeficientes e, em face de uma ideia de comunidade fechada, calcada em uma política identitária reducionista", propondo criar "comunidades mais abertas e democráticas" (ORTEGA, 2008, p. 497-498). E, particularmente nesse caso, vem se recriminando "o preconceito de certos autistas contra os neurotípicos", reconhecendo que o movimento "está caminhando para o "lado escuro" da política identitária, com sua tendência à "vitimização", “infantilidade", geradas pela demanda de um "amor incondicional e aceitação sem uma autorreflexão adulta concomitante", em vistas a 'ver luz e escuridão em si próprio, assim como no “Outro".'(ORTEGA, 2008, p. 498).

\section{considerações finais}

A sombra que projetamos sobre os autistas e outros deficientes foram absorvidas por eles e corporificada no sentido de nos assombrar, no presente, se apresentando como um artificio a ser prescrito a todos, na medida em que nos desobrigaria de uma relação com a face emocional de nossa subjetividade para viver a integralidade do desempenho e da performance cerebral. Faz-se jus dessa forma a um sistema que se centra e privilegia essas estratégias no âmbito da produção, integram esses princípios ao consumo e o revitalizam com o atual culto ao corpo, que pode ser entendido como tão compensatório quanto a concentração da subjetividade ao cérebro e do complexo sujeito a esse órgão.

O que se vê, também no caso dos militantes e da comunidade autistas, seria um tipo de funcionamento que mescla elementos históricos que se sedimentam nas representações sociais sobre seus déficits, com as exigências de performatividade física-neural almejadas pelo sistema produtivo e que traz as promessas de sua integração no mercado de consumo. Nesses casos em que tanto as altas habilidades intelectuais quanto a identidade subjetiva reduzida ao que se imprime no corpo são pleiteados pelos deficientes, como o poderiam ser por qualquer outro individuo, alcançando um nível de igualdade social, não corresponde aos níveis de dispêndio de esforço ou de energia, mesmo quando compensados por políticas 
que, em tese, ao menos formalmente, compensariam essas condições de desigualdade.

Se, singularmente, ao deficiente pouca expressividade é permitida e, raramente, uma ética da diferença própria é admitida, comunitariamente, se percebe poucas tentativas de romper com esse círculo em que a igualdade se encontre na explicitação das diferenciações e numa forma de resistência às políticas identitárias. Ao contrário, o que se vê é que o modelo autista de altas-habilidades parece representar, mais do que um modo de existência singular, com toda imperatividade cerebral e todo sofrimento psíquico que carrega, um novo índice e modelo para o desempenho eficaz do sujeito cerebral e um paradigma de inovação para certos tipos de atividades produtivas, ignorando a complexidade da experiência que os constitui e da existência que vivem.

Essa percepção parece ser ainda mais complexa para as comunidades que se formam a partir dessa experiência e dos laços existenciais que a congregam, em busca de se tornarem mais abertas e funcionarem por meio de uma política diversa daquela pautada na lógica identitária e na biopolítica neoliberal. Isso significa perspectivar uma política que se paute na convivência entre as diferentes formas de existência e que veja na diferença qualitativa de cada agrupamento, sociabilidade ou biossociabilidade um elemento crucial para o devir dessa existência capaz de tornar, eticamente, mais densa as redes relacionais do tecido social e, politicamente, mais livres as ações aí desenvolvidas.

Para que isso ocorresse seria necessário a meu ver que esse particular modo de vida que convive com os seus déficits e que não os supera em função dos acidentes que os acometeram, mas se ajusta a um modo de existência possível, ganhasse visibilidade tanto numa neuro-diversidade quanto, para criar um neologismo, numa biodiferenciação que a compreende, alargando-a e exprimindo-a como um traço físico, intelectual e, acima de tudo, cultural. Isso significa admitir a sua existência como um modo de ser ou um devir deficiente. Refiro-me aqui à deficiência não como produto de um modelo jurídico e administrativo, de um paradigma de uma racionalidade econômica e de uma política, criadas socialmente para mobilizar o sujeito para o consumo e para um empresariamento de si, 
produtor de uma performatividade que a expõe artificialmente pelo físico ou pelo desempenho intelectual. Ao contrário, refiro-me aos resultados de acidentes, que obrigam ao chamado deficiente, em razão de suas marcas fenotípicas e genotípicas que nele se inscrevem ou das deformações físicas que o acometem, a conviver com essa condição incorrigível e com um déficit motor, coordenativo ou neuronal insuperável, estruturante e significante.

É essa condição que produz um modo singular de viver e uma biossociabilidade transversa à esperada, oblíqua ao olhar vigilante da normalização e diferenciada da excentricidade propiciada pela exposição de um largo espectro narcisista. Essa biossociabilidade diferenciada na qual se engajam aqueles que mesmo incluídos, ainda se sentem fora do sistema de consumo por esse modo singular de ser, parece exprimir um movimento oblíquo e distinto daquele capitaneado pela racionalidade econômica e pelo paradigma biopolítico da deficiência. Afinal, eles reclamam uma base ética para esta última e uma ontologia da deficiência ${ }^{4}$ não somente incompreendidas por aquela racionalidade e paradigma, como também como um contraponto a eles, gerando formas de resistência aos dispositivos de controle da vida e às tecnologias do biopoder existentes.

É essa face ética, ontológica e política que me parece merecer maior atenção e investimento por parte dos estudos em Filosofia da Educação, já que podem encontrar aí um campo não apenas de interface com a Educação Especial, como também de experimentação da prática filosófica em educação.

\section{referências}

CARVALHO, Alexandre Filordi. Por uma ontologia política da (d)eficiência no governo da infância. In: RESENDE, Haroldo de. Michel Foucault: o governo da infância. Belo Horizonte: Editora Autêntica, 2015, pp. 25-47.

\footnotetext{
4 Essa ética e o que se tem denominado por ontologia da deficiência, tem sido explorada recentemente por Alexandre Filordi de Carvalho (2015) a partir da lógica da diferença de Deleuze e Guattari e por Pedro Angelo Pagni (2015) à luz da ontologia do acidente de Catherine Malabou (2007) e da estética da existência foucaultiana. Também pode se encontrar outras interpretações acerca do assunto, assim como perspectivas distintas, neste dossiê, que se propõe justamente a discutir essas interfaces.
} 
da exclusão a um modelo identitário de inclusão: a deficiência como paradigma biopolítico*

CANGUILHEM, Georges. O normal e o patológico. 6.ed. Rio de Janeiro: Forense Universitária, 2009.

CASTEL, Robert. La gestión de los riesgos. Barcelona: Anagrama, 1999.

FABRIS, Eli T. Henn; KLEIN, Rejane Ramos. (orgs). Inclusão e biopolítica. Belo Horizonte: Autêntica, 2013.

FOUCAULT, Michel. A governamentalidade. In: Microfísica do Poder. 9. Ed. Rio de Janeiro: Graal, 1990, p. 277-293.

FOUCAULT, Michel. História da Sexualidade: vontade de saber. V. I. Rio de Janeiro: Graal, 1997.

FOUCAULT, M. O Governo de si e dos outros. São Paulo: Martins Fontes, 2010.

LAZZARATO, Maurizio. Signos, Máquinas, subjetividades. São Paulo : N-1 edições, 2014.

MALABOU, Catherine. Ontologie de l'accident: essai sur la plasticité destructrice. París: Éditions Léo Scheer, 2009.

ORTEGA, Francisco. Práticas de ascese corporal e constituição de bioidentidades, Cadernos de saúde coletiva. 2003, vol. 11, n. 1, p. 55-77.

ORTEGA, Francisco. Da ascese à bio-ascese ou do corpo submetido à submissão ao corpo. In: RAGO, Margareth; ORLANDI, Luiz B. Lacerda; VEIGA-NETO, Alfredo. Imagens de Foucault e Deleuze: ressonâncias nietzschianas. Rio de Janeiro: DP\&A, 2005, p.139-173.

ORTEGA, Francisco. O sujeito cerebral e o movimento da neurodiversidade. Mana, Rio de Janeiro, 14 (2): 14(2): 477-509, out.2008.

PAGNI, Pedro Angelo. Diferença, subjetivação e educação: um olhar outro sobre a inclusão escolar. Pro-Posições [online]. 2015, vol.26, n.1, pp. 87-103.

RABINOW, Paul. Artificialidade e iluminismo: da sociobiologia à biossociabilidade. In: RABINOW, Paul. Antropologia da razão. Rio de Janeiro: Relume Dumará, 1999, pp. 135-158.

REVEL, Judith. Biopolítica. In: _ Michel Foucault: conceitos elementares. São Carlos: Claraluz, 2005, p. 26-28.

TREMAIN, Shelley (ed.). Foucault and the government of desability. Michigan: University Michigan Press, 2005.

VEIGA-NETO, Alfredo. Foucault \& a Educação. Belo Horizonte: Autêntica, 2004.

recebido em: 30.05 .2016

aceito em: 09.08.2016 